\title{
Acclimation of Red Sea macroalgae to solar radiation: photosynthesis and thallus absorptance
}

\author{
Félix L. Figueroa ${ }^{1, *}$, Brezo Martínez ${ }^{2}$, Alvaro Israel $^{3}$, Amir Neori ${ }^{4}$, Erik-jan Malta ${ }^{5}$, \\ Put Ang Jr. ${ }^{6}$, Sven Inken ${ }^{7}$, Ronny Marquardt ${ }^{8}$, Tamar Rachamim ${ }^{3}$, Uri Arazi ${ }^{3}$, Sammy \\ Frenk $^{3}$, Nathalie Korbee ${ }^{1}$
}

${ }^{1}$ Departamento de Ecología, Facultad de Ciencias, Universidad de Málaga, Campus Universitario de Teatinos s/n, 29071 Málaga, Spain

${ }^{2}$ Área de Biodiversidad y Conservación, Universidad Rey Juan Carlos, Departamental I, Despacho 213, C/ Tulipán s/n, 28933 Móstoles, Madrid, Spain

${ }^{3}$ Israel Oceanographic \& Limnological Research Ltd., The National Institute of Oceanography, PO Box 8030, Haifa 31080, Israel

${ }^{4}$ Israel Oceanographic \& Limnological Research Ltd., National Center for Mariculture, PO Box 1212, Eilat 88112, Israel

${ }^{5}$ ALGAE-Marine Plant Ecology Research Group, CCMAR, Universidade do Algarve, Gambelas, 8005-139 Faro, Portugal

${ }^{6}$ Department of Biology, The Chinese University of Hong Kong, Shatin, N.T., Hong Kong SAR, China

${ }^{7}$ School of Biological Sciences, Monash University, Clayton, Victoria 3800, Australia

${ }^{8}$ Institute for Biosciences, Aquatic Ecology, University of Rostock, Albert-Einstein-Str. 3, 18059 Rostock, Germany

\begin{abstract}
Thallus absorptance, daily courses of maximal quantum yields of chlorophyll fluorescence of photosystem II $\left(F_{\mathrm{v}} / F_{\mathrm{m}}\right)$ and electron transport rates (ETR) were determined in 3 macroalgae (Hypnea spinella, Rhodophyta; Sargassum vulgare, Phaeophyta; and Ulva lactuca, Chlorophyta) collected from a low nutrient supply (LNS) ecosystem (Red Sea, Gulf of Aqaba, Eilat, Israel). In addition, U. lactuca grown previously in high nutrient supply (HNS) fishpond effluents was used to evaluate the effect of nutrient enrichment on photosynthesis. Short-term (2 d) and mid-term (5 d) effects of both photosynthetically active radiation (PAR) and full solar irradiance (PAB: PAR+UVA+UVB) at 3 solar irradiance treatments (no neutral filters, no NF; 2 neutral filter layers, 2NF; and 4 neutral filter layers, 4NF simulating levels of irradiance at 5, 10 and $20 \mathrm{~m}$ depth respectively) were evaluated in algae incubated with running seawater. Significant effects of time (variation throughout the day) and irradiance (number of neutral filters) on both $F_{\mathrm{v}} / F_{\mathrm{m}}$ and ETR were observed. Photoinhibition occurred at noon under the no NF (up to $40 \%$ decrease) and 2NF (up to $30 \%$ decrease) treatments; however, full recovery in all treatments was reached in the afternoon (dynamic photoinhibition) except in H. spinella. The highest maximum ETR was observed in the no NF treatment despite its strongest photoinhibitory effect. The decrease in $F_{\mathrm{v}} / F_{\mathrm{m}}$ at noon was similar to or higher under the PAB than under the PAR treatment alone, depending on the species. Photoinhibition was lower and the maximum ETR was higher in HNS than in LNS U. lactuca, indicating positive effects of nutrient supply on both photosynthesis and photoprotection. The maximum ETRs exhibited by different algae may be related to their zonation in the field and the resulting energy supply.
\end{abstract}

KEY WORDS: Chlorophyll fluorescence $\cdot$ Hypnea spinella $\cdot$ Macroalgae $\cdot$ Nutrient supply $\cdot$ Red Sea Sargassum vulgare $\cdot$ Thallus absorptance $\cdot$ Ulva lactuca Resale or republication not permitted without written consent of the publisher

\section{INTRODUCTION}

Seaweeds generally live in a highly dynamic light environment (Lüning 1990). Both total irradiance and light quality, especially ultraviolet radiation (UVR), show strong diurnal fluctuations that are further influenced by the attenuation properties of the water column. Increased UVB radiation due to ozone depletion reduces growth and primary productivity of seaweeds (Bischof et al. 2006). The effect of UVR on the photo- 
synthetic activity of seaweeds from polar and temperate regions has been extensively evaluated both in field and laboratory studies using oxygen electrodes or in vivo chlorophyll fluorescence (Enríquez et al. 1995, Häder \& Figueroa 1997, Bischof et al. 2006). However, only a limited number of reports on tropical algal photosynthesis is available (Hanelt et al. 1994, Payri et al. 2001). Intertidal and subtidal tropical macroalgae have been surveyed for their photosynthetic responses and for the quantification of their pigments (Payri et al. 2001, Godínez-Ortega et al. 2008).

Most temperate and cold water intertidal seaweeds exhibit dynamic photoinhibition, expressed e.g. as a decrease in photosynthesis at noon that recovers to morning values in the afternoon (Figueroa et al. 1997, Hanelt et al. 1997, Gómez et al. 2004, Bischof et al. 2006). An evaluation of the effect of UVB on algal photosynthesis is crucial to the understanding of carbon flow in the ocean, especially considering the global climate change scenario (Bellwood et al. 2004). Algal acclimation to increased UVR has also been shown to be related to the availability of nutrients, such as nitrate and ammonium (Korbee Peinado et al. 2004, Huovinen et al. 2006).

The clear and oligotrophic waters of the Red Sea allows a high penetration of photosynthetically active radiation (PAR) and UVR (Stambler 2005); nevertheless, the effect of UVR on macroalgal photosynthesis in the Red Sea has never been evaluated. Indeed, most studies on photosynthesis and photoacclimation have been conducted on corals, phytoplankton (Falkowski \& Dubinsky 1981, Beer et al. 1998a, Bellwood et al. 2004) and marine angiosperms such as Halophila ovalis (Beer et al. 1998b), which are the dominant groups in shallow benthic environments of the Red Sea. In recent years, an increase in the macroalgal biomass in the Red Sea has become apparent, and has mainly been attributed to both nutrient enrichment from urban and aquaculture effluents, and decreased herbivory, i.e increase in macroalgal biomass due to a decrease in herbivory brought about by overfishing (Lapointe 1997, Bellwood et al. 2004). Genin et al. (1995) reported nutrient regulation of macroalgal blooms on coral reefs in the Gulf of Aqaba, where atmospheric cooling following the eruption of Mt. Pinatubo in 1991 led to vertical mixing, nutrient enrichment and large-scale overgrowth of macroalgae that directly caused coral death.

In order to address the acclimation responses of subtropical seaweeds to varying levels of irradiance and UVR, 3 marine macroalgae from the Gulf of Aqaba were collected and incubated at different irradiance and UV conditions. Daily cycles of photosynthesis (electron transport rate, ETR) and photoinhibition (decreases in both maximum quantum yield $\left(F_{\mathrm{v}} / F_{\mathrm{m}}\right)$ and maximum ETR) were determined after 2 and $5 \mathrm{~d}$ of incubation. Furthermore, the influence of nutrient status and UVR on photosynthetic activity was also evaluated by comparing the ETR and $F_{\mathrm{v}} / F_{\mathrm{m}}$ of Ulva lactuca collected from the sea and $U$. lactuca grown in an aquaculture system under high nutrient supply (HNS) from fishpond effluents. The role of HNS in enhancing photosynthetic activity and reducing photoinhibition in U. lactuca was assessed in the light of a related study comparing the growth and photosynthetic performance of $U$. lactuca grown in tanks under high and low nutrient supplies (Figueroa et al. 2009, this Theme Section). It is hypothesized that macroalgae of the Red Sea show efficient mechanisms of acclimation to both high PAR irradiance and UVR, i.e dynamic photoinhibition. In addition, it is expected that algae previously grown under N-replete conditions in culture would show higher capacity for photoacclimation than algae grown naturally in the Red Sea under low nutrient levels.

\section{MATERIALS AND METHODS}

Algae. The algae investigated in this study were Hypnea spinella (C. Agardh) Kützing (Rhodophyta), Sargassum vulgare C. Agardh (Phaeophyta) and Ulva lactuca Linnaeus (Chlorophyta), which were all collected from the Gulf of Aqaba in the Red Sea on 1 April 2008 at $1-4 \mathrm{~m}$ depth. Ulva lactuca was also cultured in ambient, low nutrient supply (LNS) seawater or in high nutrient supply (HNS) seawater with fishpond effluents at the National Center for Mariculture (Israel Oceanographic \& Limnological Research). Growth conditions of $U$. lactuca in the aquaculture system are reported in Figueroa et al. (2009).

Nutrients. Nutrient levels under HNS in the cultivation system and of ambient seawater from the Red Sea are indicated in Table 1. Samples for total ammonia-N (TAN), nitrite-N, nitrate-N and orthophosphate-P from HNS tanks were taken on 3 separate days $(n=9)$. Samples from the Red Sea were taken from seawater that was pumped directly to the facilities of the Interuniversity Institute for Marine Sciences (IUI) at Eilat (Israel).

Table 1. Mean $( \pm \mathrm{SE})$ nutrient concentrations $\left(\mu \mathrm{mol}^{-1}\right)$ of seawater with high nutrient supply (HNS) used to culture Ulva lactuca, and in the seawater collected from the Red Sea where the algae were harvested. TAN: total ammonium-N

\begin{tabular}{|lcccc|}
\hline Sample & TAN & Nitrite-N & Nitrate-N & Orthophosphate-P \\
\hline HNS & $28.4 \pm 1.8$ & $64.8 \pm 1.6$ & $239.4 \pm 5.1$ & $16.1 \pm 0.2$ \\
Red Sea & $5.0 \pm 0.6$ & $0.017 \pm 0.003$ & $0.28 \pm 0.03$ & $0.128 \pm 0.005$ \\
\hline
\end{tabular}


Approximately $8 \mathrm{ml}$ of seawater from the tanks were collected using sterile syringes and $0.45 \mu \mathrm{m}$ disposable filters (Mod. Supatop Syringe Filter CA 0.45 $\mu \mathrm{m}, 33 \mathrm{~mm}$, Anachem), and immediately frozen at $-20^{\circ} \mathrm{C}$. Nutrient analysis was done using a semicontinuous flow autoanalyzer (Mod. SAN ++, SKALAR, Breda) following standard protocols (Grasshoff et al. 1983).

Experimental design. The algae were incubated in cylindrical cages $(15 \mathrm{~cm}$ diameter, $35 \mathrm{~cm}$ long) that were constructed with white plastic net $(0.5 \mathrm{~cm}$ mesh diameter) and submerged in a rectangular fiberglass tank ( $2 \mathrm{~m}$ long, $1 \mathrm{~m}$ wide, and $20 \mathrm{~cm}$ high) that was filled with running seawater directly supplied from the Red Sea (IUI facilities). To simulate different depths based on the average attenuation coefficient $\left(K_{\mathrm{d}, \mathrm{PAR}}\right)$ of $0.054 \mathrm{~m}^{-1}$ for Red Sea waters reported by Stambler (2005), the cylinders were covered with neutral filters (grey nets) as follows: (1) cages not covered with neutral grey filters (no NF) that experienced a reduction of $\sim 25 \%$ PAR, thus simulating the irradiance condition at $5 \mathrm{~m}$ depth of water; (2) cages covered with 2 layers of neutral grey filters ( $2 \mathrm{NF}$ ) that had a $60 \%$ reduction of PAR, simulating water at $10 \mathrm{~m}$ depth; and (3) cages covered with 4 layers of neutral grey filters (4NF) that had an $80 \%$ reduction of PAR, simulating water at a depth of $20 \mathrm{~m}$ (see Fig.1).

In addition, 2 light quality treatments were applied: full solar radiation (PAB: PAR+UVA+UVB) and PAR only treatment. To provide different light conditions, UV cut-off filters were used according to Villafañe et al. (2003): for PAB, Ultraphan 295 (Digefra), and for PAR alone, Ultraphan 395 (Digefra).

A total of 24 cages was used for a 3 simulated depth (incident irradiance) $\times 2$ light (UV) treatment factorial experimental design with 4 replicates per treatment. The percentages of transmitted PAR, UVA and UVB in the different treatments (combination of cut-off UV and grey neutral filters) are given in Table 2 .

Light measurements. Irradiances of PAR (400-700 nm), UVA (315-400 nm) and UVB (280-315 nm) were determined approximately every $1.5 \mathrm{~h}$. In addition, the spectral characteristics (280$800 \mathrm{~nm}$ ) of the incubators (cylindrical cages constructed with white plastic nets, and covered with neutral and UV cut-off filters) were determined using a multiphotodiode spectroradiometer (SMS-500, Sphere Optics).

Thallus absorptance. The absorptance in the PAR region of the solar radiation spectra (400-700 nm) was determined using a cosine corrected sensor that was connected to the multiphotodiode SMS 500 spectroradiometer and calculated using the following equation (Beer et al. 2000):

$$
\mathrm{A}=1-\left(E_{\mathrm{t}} \times E_{\mathrm{o}}^{-1}\right) \quad \text { (relative units) }
$$

where $E_{\mathrm{o}}$ is the incident irradiance of PAR and $E_{\mathrm{t}}$ is the transmitted irradiance with the algae being located on the light sensor.

The sensor was covered with black plastic except for a slot of $0.5 \mathrm{~cm}$ width. In each case, the incident irradiance $\left(E_{0}\right)$ was first measured. A piece of the algal thallus was then placed on this slot and the spectral light transmission determined $\left(E_{\mathrm{t}}\right)$. Two light sources were used: solar radiation (direct irradiance) and a high pressure sodium lamp (Osram, 200W) located $0.75 \mathrm{~m}$ above at a $90^{\circ}$ angle to the flat surface of the sensor. No differences in the measurements were observed from these 2 different light sources. Six pieces of thallus from different independent specimens of each species were used in the measurements.

Photosynthetic rate as in vivo chlorophyll fluorescence. Two Diving-PAMs, one PAM-2000 and one Water-PAM (Walz) were used. Intercalibration of the PAM fluorometers was conducted until no significant differences ( $t$-test, $\mathrm{p}=0.055, \mathrm{n}=12$ ) in the photosynthetic yield remained. The maximum quantum yield $\left(F_{\mathrm{v}} / F_{\mathrm{m}}\right)$ was determined after pre-incubation in darkness for at least 30 min (Figueroa et al. 2003). $F_{\mathrm{v}}$ is the difference between the maximum fluorescence from a fully closed photosystem II (PSII) reaction center $\left(F_{\mathrm{m}}\right)$ and the initial fluorescence $\left(F_{\mathrm{o}}\right)$ from the antenna system of the open PSII reaction centre (Schreiber et al. 1995). The effective quantum yield $\left(\Delta F / F^{\prime}{ }_{m}\right)$ was calculated according to Genty et al. (1989) as $\left(F_{\mathrm{m}}-F_{\mathrm{t}}\right) \times F^{\prime}{ }_{\mathrm{m}}^{-1}$, where $F_{\mathrm{t}}$ is the current steady-state fluorescence in light adapted algae, while $F_{m}^{\prime}$ is the maximum fluorescence induced by a saturating white light pulse (800 ms, $6000 \mu \mathrm{mol}$ photons $\mathrm{m}^{-2} \mathrm{~s}^{-1}$ ). Electron transport rate (ETR) was calculated as

$$
\mathrm{ETR}=\Delta F / F_{\mathrm{m}}^{\prime} \times E \times A \times F_{\text {II }}\left(\mu \mathrm{mol} \text { electrons } \mathrm{m}^{-2} \mathrm{~s}^{-1}\right)
$$

where $E$ is the incident solar radiation, $A$ is the absorptance, and $F_{\mathrm{II}}$ is the fraction of chl $a$ in PSII that is associated with its light harvesting center (LHCII) and is

Table 2. Percentage of transmitted irradiance (mean $\pm \mathrm{SE}$ ) of photosynthetically active radiation (PAR, 400-700 nm), UVA radiation $(315-400 \mathrm{~nm}$ ) and UVB radiation (280-315 $\mathrm{nm}$ ) in different treatments: PAR (with $395 \mathrm{~nm}$ cut-off filter) and PAB (PAR+UVA+UVB, with 295 nm cut-off filter) combined with different numbers of layers of neutral grey filters. $n=4$

\begin{tabular}{|lcrrr|}
\hline \multirow{2}{*}{ Treatment } & Radiation & \multicolumn{3}{c|}{ Number of layers of neutral filters -} \\
\cline { 3 - 5 } & & \multicolumn{1}{c}{0} & 2 & 4 \\
\hline \multirow{2}{*}{ PAR } & PAR & $75.69 \pm 2.71$ & $39.74 \pm 2.89$ & $19.89 \pm 2.16$ \\
& UVA & $6.68 \pm 0.63$ & $3.96 \pm 0.45$ & $2.18 \pm 0.32$ \\
& UVB & $1.49 \pm 1.40$ & $0.73 \pm 2.53$ & $0.56 \pm 1.64$ \\
PAB & PAR & $74.82 \pm 1.34$ & $39.54 \pm 2.02$ & $19.18 \pm 0.60$ \\
& UVA & $50.86 \pm 3.15$ & $28.90 \pm 3.51$ & $12.74 \pm 0.51$ \\
& UVB & $45.95 \pm 4.05$ & $31.20 \pm 4.13$ & $13.72 \pm 0.95$ \\
\hline
\end{tabular}


related to the absorbed quanta of PSII (400-700 nm). Values for $F_{\text {II }}$ were taken from Grzymski et al. (1997), namely 0.5 for Chlorophyta, 0.15 for Rhodophyta and 0.8 for Phaeophyta. $F_{\mathrm{v}} / F_{\mathrm{m}}$, ETR and thallus absorptance were determined at different time courses: 2 and $5 \mathrm{~d}$ after algal harvesting (3 and 6 April respectively).

Statistical analysis. Hierarchical ANOVA was carried out to test for differences in mean $F_{\mathrm{v}} / F_{\mathrm{m}}$ after subjecting the algae to 6 combinations of 3 levels of incoming PAR (simulating 3 depths, Factor 1: neutral filter ' $N$ ') and 2 UV treatments (Factor 2: UV), as explained above. A third factor, hourly irradiance, $\left(t_{\mathrm{i}}\right.$, with time $t$ being Factor 3), was also included in the analysis, since different algal samples were taken at different times during the daily cycle. On 3 April, between 2 to 12 replicate data taken at 9:00, 11:00, 13:00, 15:00 and 17:00 $\mathrm{h}$ were used in the ANOVA. Between 5 to 11 replicate data per cylinder taken at 12:00, 14:00 and

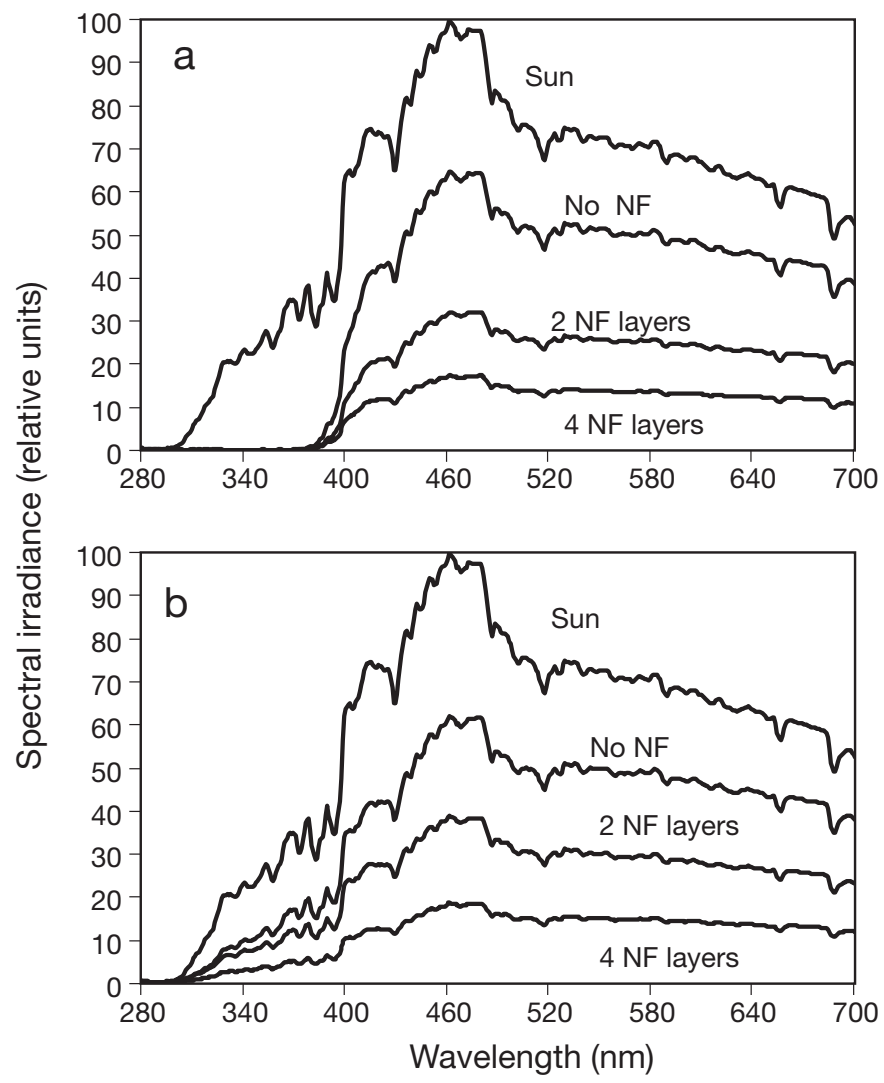

Fig. 1. Relative spectral characteristics of the chambers (cylindrical cages constructed of plastic net) used in the experiments. Spectral characteristics are expressed as percentages of spectral irradiance of the sun at noontime with (a) PAR treatment transmitting only photosynthetically active radiation (PAR, $\lambda=400-700 \mathrm{~nm}$ ), and (b) PAB treatment transmitting PAR, UVA (315-400 nm) and UVB (295-315 nm). Different layers of neutral filters (grey nets) were used to simulate the PAR irradiance at different depths: no neutral filters (no NF, $5 \mathrm{~m}$ depth), 2 layers (2NF, $10 \mathrm{~m}$ depth) and 4 layers (4NF, $20 \mathrm{~m}$ depth)
18:00 h were analyzed for the 6 April data (replicates for the full design are available from the first author). Minor variations in environmental conditions between different cylinders may, to some extent, affect the response of the algae. To test for this effect, 2 cylinders per combination of treatments were grouped as a set, and cylinder (nested in the neutral filter $\times$ UV interaction) was included as an additional factor in the ANOVA. In the case of Ulva lactuca, since algae from the aquaculture facilities were compared to field collected individuals, an additional factor (origin, $O$ ) was crossed with those mentioned above and included in the analyses. Cochran's test was used to test for heterogeneity of variances (Underwood 1997). All tests were done with SPSS 14.0 for Windows.

\section{RESULTS}

\section{Hourly irradiance}

The hourly irradiances were slightly higher on 3 April ( $2 \mathrm{~d}$ after the start of the experiment or algal harvesting) than on 6 April 2008 (5 d after) (data not shown). The maximum irradiance reached at around 14:00 $\mathrm{h}$ (local time) was $\sim 1660 \mu \mathrm{mol} \mathrm{m}^{-2} \mathrm{~s}^{-1}$ of PAR, $41 \mathrm{~W} \mathrm{~m}^{-2}$ of UVA and $1.2 \mathrm{~W} \mathrm{~m}^{-2}$ of UVB. The UV/PAR ratios ranged from 0.08 to 0.14 (maximum values in the afternoon). The average ratio of UVB/UVA was 0.028 . The irradiance close to the thalli was reduced compared to the incident solar irradiance due to light absorption by the vessels and filters used (Fig. 1, Table 2).

\section{Maximum quantum yield $\left(F_{\mathrm{v}} / F_{\mathrm{m}}\right)$}

For Hypnea spinella, the $F_{\mathrm{v}} / F_{\mathrm{m}}$ decreased at noon. This was especially clear at the highest irradiance treatment (no NF, Fig. 2). After $2 \mathrm{~d}$ of incubation (on 3 April, with no NF), the percentage of decrease (\%D) was 2 times higher in PAR than in PAB. However, with $2 \mathrm{NF}$, the reverse was recorded and no differences were observed with $4 \mathrm{NF}$. After $5 \mathrm{~d}$ (on 6 April), \%D was 2.2 times higher in PAB than in PAR with no NF. The percentage of recovery $\left(\% \mathrm{R}, F_{\mathrm{v}} / F_{\mathrm{m}}\right.$ values in the afternoon compared to morning values), was generally higher under PAB than under PAR except with 2NF. Full recovery was reached in all treatments except under $2 \mathrm{NF}$.

When considering the whole data set, no significant differences were found between PAR and PAB treatments after $2 \mathrm{~d}$ (UV treatment alone: $F_{1,6}=0.02, \mathrm{p}=$ $0.882 ; \mathrm{p}>0.05$ for all interaction terms including UV, not shown). Thus, UVR did not produce any further decrease in $F_{\mathrm{v}} / F_{\mathrm{m}}$ and after $2 \mathrm{~d}$, only the hourly irradiance $\left(t_{\mathrm{i}}\right)$ was significantly different $\left(t_{\mathrm{i}}\right.$ treatment alone: 

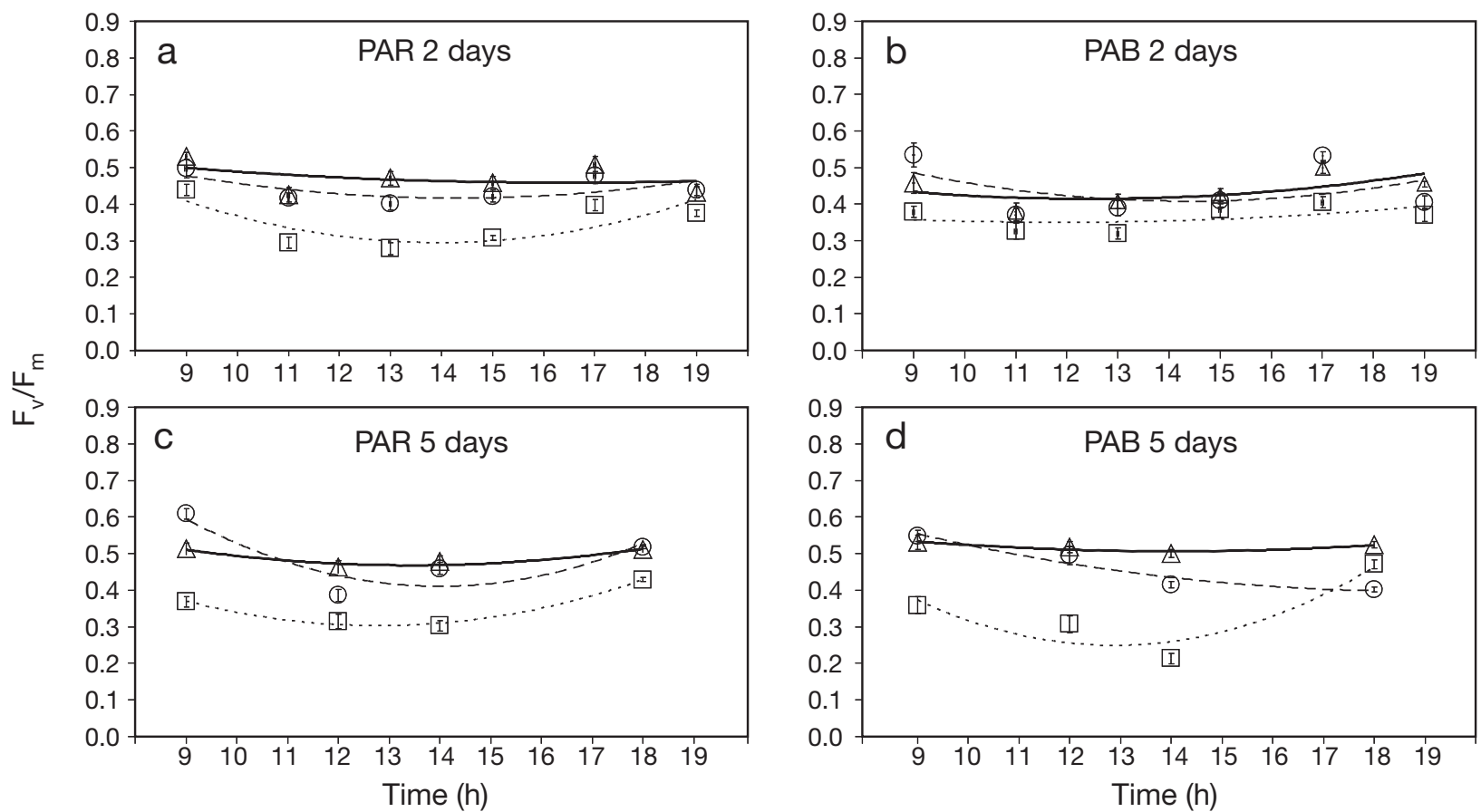

Fig. 2. Hypnea spinella. Mean $( \pm \mathrm{SE})$ daily cycles of maximum quantum yield $\left(F_{\mathrm{v}} / F_{\mathrm{m}}\right)$ of algae collected from the Red Sea at $3-4 \mathrm{~m}$ depth on 1 April 2008. $F_{\mathrm{v}} / F_{\mathrm{m}}$ was determined after $2 \mathrm{~d}$ (3 April 2008) $(\mathrm{a}, \mathrm{b})$ and $5 \mathrm{~d}$ (6 April 2008) (c,d) of experiments in algae incubated under PAR and PAR+UVA+UVB (PAB) treatments at 3 different solar irradiances which were obtained using neutral filters to simulate the PAR irradiance at different depths: no neutral filters (no NF, $5 \mathrm{~m}$ depth, $\square$ and $\cdots \cdots)$ ), layers $(2 \mathrm{NF}, 10 \mathrm{~m}$ depth, $\mathrm{O}$ and ----$)$ and 4 layers (4NF, $20 \mathrm{~m}$ depth, $\Delta$ and - )

$F_{3,18}=9.63, \mathrm{p}=0.001 ; \mathrm{p}>0.05$ for all interaction terms including $t_{\mathrm{i}}$, not shown). However, after $5 \mathrm{~d}$, the combination of neutral filters $(N)$, hourly irradiance $\left(t_{\mathrm{i}}\right)$ and UV treatments produced significant differences (interaction $\left.N \times t_{1} \times \mathrm{UV}: F_{4,12}=4.25, \mathrm{p}=0.023\right)$. Lowering the irradiance by using neutral filters (simulating different depths) further decreased $F_{\mathrm{v}} / F_{\mathrm{m}}$ through the day, with the decrease being higher under 2NF (10 m depth) than under $4 \mathrm{NF}$ (20 m depth). No hourly variation in $F_{\mathrm{v}} / F_{\mathrm{m}}$ was observed under $4 \mathrm{NF}$ (Fig. $2 \mathrm{c}, \mathrm{d}$ ). $F_{\mathrm{v}} / F_{\mathrm{m}}$ decreased significantly at noon and in the presence of UVR after $5 \mathrm{~d}$ of exposure (Fig. 2c,d).

For Sargassum vulgare, the variations in irradiance due to treatments simulating different depths (layers of neutral filter), different times during the day, and the combined UV treatments produced differences in $F_{\mathrm{v}} / F_{\mathrm{m}}$ (Fig. 3). Algae incubated at the highest irradiance (no NF) exhibited the lowest $F_{\mathrm{v}} / F_{\mathrm{m}}$ values (Fig. 3). After $5 \mathrm{~d}$, the neutral filter $(N) \times$ hourly irradiance $\left(t_{\mathrm{i}}\right) \times \mathrm{UV}$ interaction was significant $\left(F_{4,12}=4.62, \mathrm{p}=0.017\right)$. This contrasts with the results after $2 \mathrm{~d}$ of exposure $\left(N \times t_{\mathrm{i}} \times\right.$ UV interaction: $F_{8,24}=1.03, \mathrm{p}=0.442$ ) where only the interaction term $N \times t_{\mathrm{i}}$ was significant $\left(F_{8,24}=2.99, \mathrm{p}=\right.$ 0.018). UVR did not produce any additive major effect on $F_{\mathrm{v}} / F_{\mathrm{m}}$ although significant differences were observed due to interaction with other variables after $5 \mathrm{~d}$. After $2 \mathrm{~d}$ under the no NF treatment, $F_{\mathrm{v}} / F_{\mathrm{m}}$ was only slightly lower under PAB than under PAR. This trend was reversed with the reduction of incident light using the neutral filters, i.e. the presence of UV slightly reduced the lowering of $F_{\mathrm{v}} / F_{\mathrm{m}}$ when compared to that under PAR only (Fig. 3). After $5 \mathrm{~d}$ of exposure, $F_{\mathrm{v}} / F_{\mathrm{m}}$ was higher in the PAB than in the PAR treatments. $F_{\mathrm{v}} / F_{\mathrm{m}}$ was also only higher after $5 \mathrm{~d}$ than after $2 \mathrm{~d}$ of incubation under no NF (Fig. 3). \%D was higher after $2 \mathrm{~d}$ than after $5 \mathrm{~d}$ of exposure. After $2 \mathrm{~d}$, \% D was $~ 1.4$ times higher in the no NF and 2NF treatments under PAR and PAB respectively. However, no clear differences in the no NF and 2NF treatments were observed between the PAR and PAB treatments after $5 \mathrm{~d}$. Despite its decrease at noon, $F_{\mathrm{v}} / F_{\mathrm{m}}$ increased again in the afternoon, reaching similar or higher values than those recorded in the morning $(\% \mathrm{R}>100 \%)$.

For Ulva lactuca collected from the Red Sea, the variations in irradiance due to treatments simulating different depths (layers of neutral filters $N$ ), hourly irradiance $\left(t_{i}\right)$ throughout the dayand the combined UV and simulated depth treatments produced significant differences in $F_{\mathrm{v}} / F_{\mathrm{m}}$ (Fig. 4). No or only minor variations in $F_{\mathrm{v}} / F_{\mathrm{m}}$ between $2 \mathrm{NF}$ and $4 \mathrm{NF}$ (simulating 10 and $20 \mathrm{~m}$ depths respectively) were observed (Fig. 4), whereas a clear decrease in $F_{\mathrm{v}} / F_{\mathrm{m}}$ at noon was recorded with no NF (simulating $5 \mathrm{~m}$ depth) mainly after $5 \mathrm{~d}$ of the experiment (Fig. $4 ; N \times t_{\mathrm{i}}$ interactions: $F_{8,48}=4.47$, 

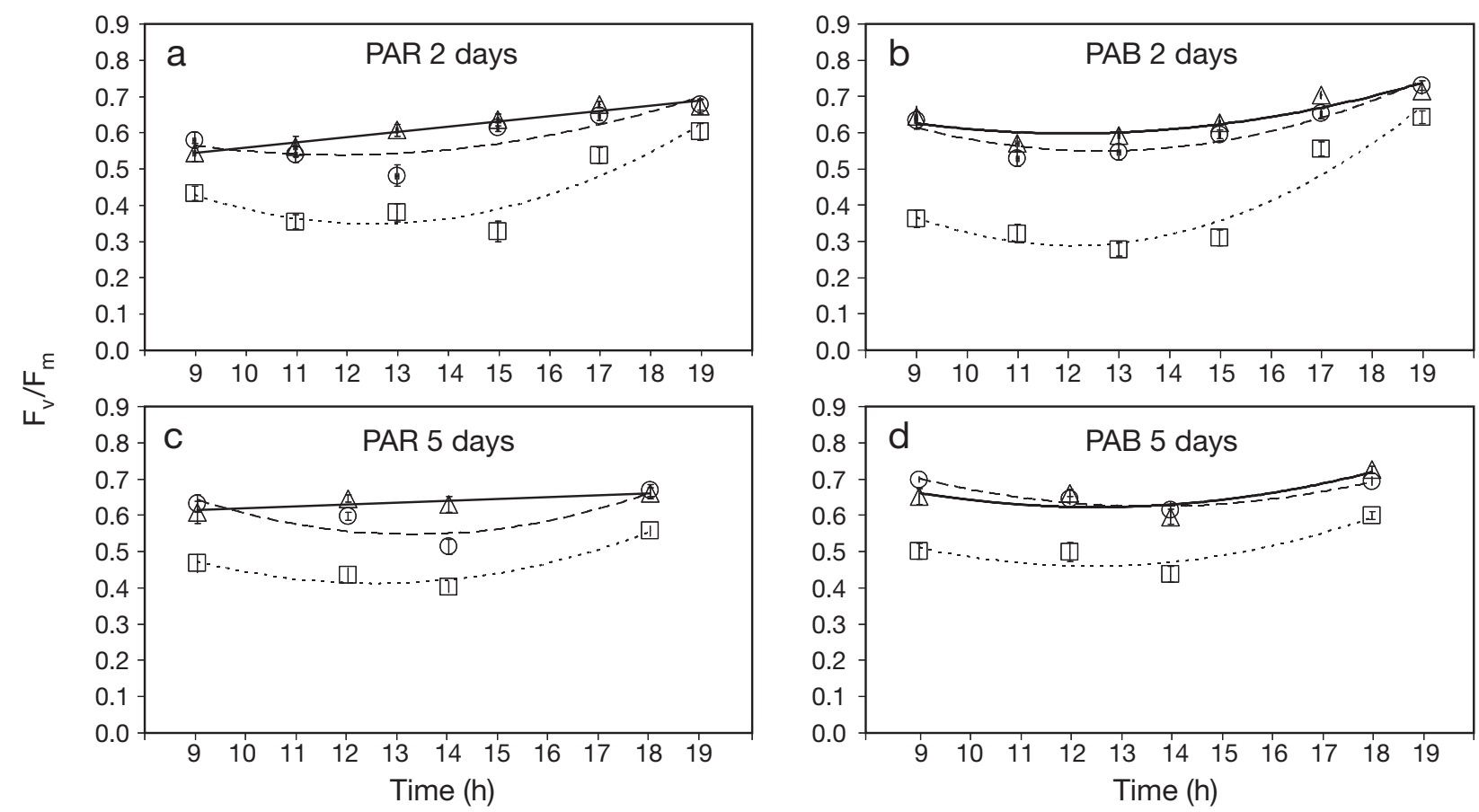

Fig. 3. Sargassum vulgare. Mean $( \pm \mathrm{SE})$ daily cycles of maximum quantum yield $\left(F_{\mathrm{v}} / F_{\mathrm{m}}\right)$ of algae collected from the Red Sea at 2-3 m depth on 1 April 2008. $F_{\mathrm{v}} / F_{\mathrm{m}}$ was determined after $2 \mathrm{~d}$ (3 April 2008) (a,b) and $5 \mathrm{~d}$ (6 April 2008) (c,d) of experiments in algae incubated under PAR and PAR+UVA+UVB (PAB) treatments at 3 different solar irradiances which were obtained using neutral filters to simulate the PAR irradiance at different depths: no neutral filters (no NF, $5 \mathrm{~m}$ depth, $\square$ and $\cdots \cdots$ ), 2 layers (2NF, $10 \mathrm{~m}$ depth, $\mathrm{O}$ and --- $)$ and 4 layers (4NF, $20 \mathrm{~m}$ depth, $\triangle$ and $\longrightarrow$ )
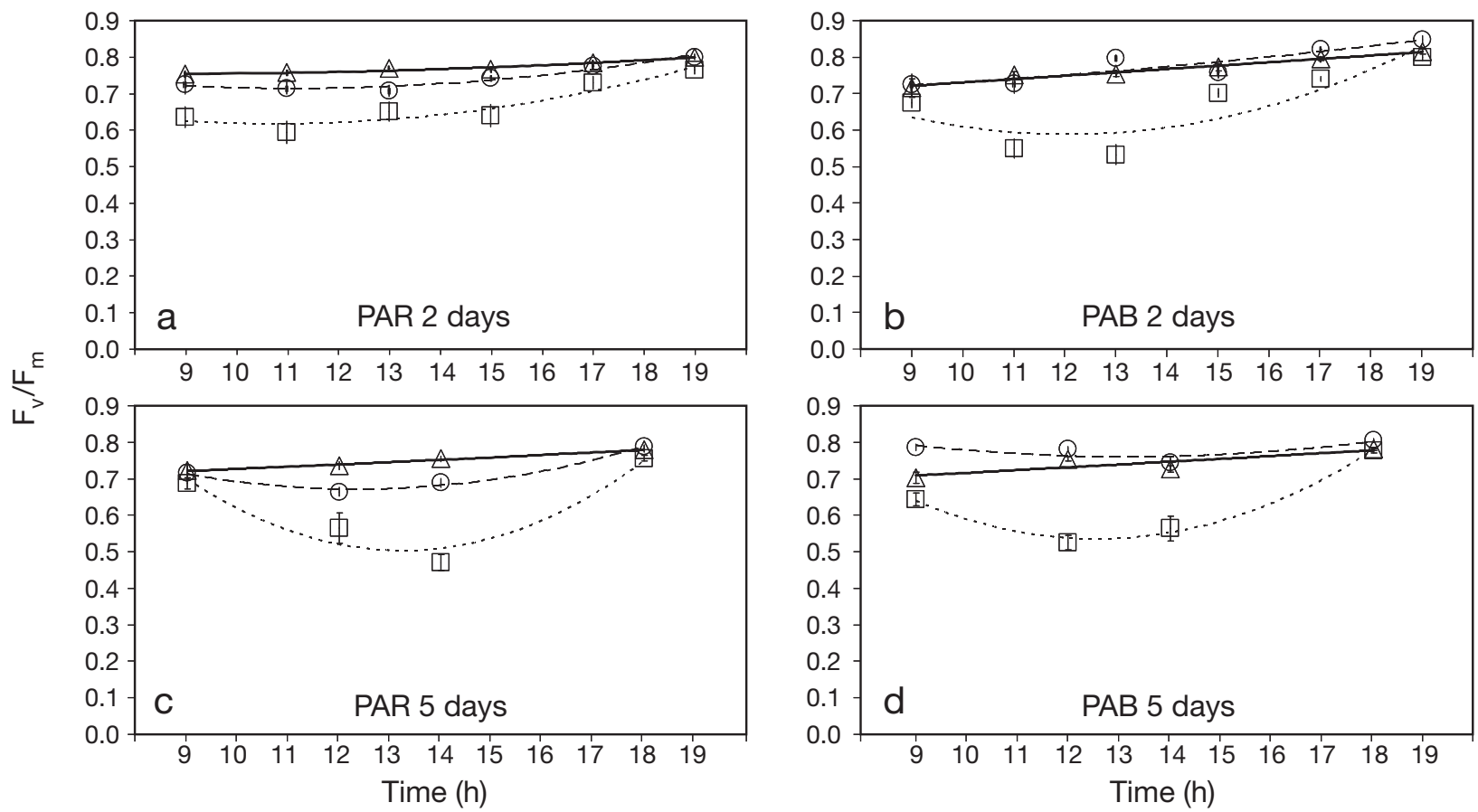

Fig. 4. Ulva lactuca. Mean $( \pm \mathrm{SE})$ daily cycles of maximum quantum yield $\left(F_{\mathrm{v}} / F_{\mathrm{m}}\right)$ of algae collected from the Red Sea at $1-2 \mathrm{~m}$ depth on 1 April 2008. $F_{\mathrm{v}} / F_{\mathrm{m}}$ was determined after $2 \mathrm{~d}$ (3 April 2008) (a,b) and $5 \mathrm{~d}$ (6 April 2008) (c,d) of experiments in algae incubated under PAR and PAR+UVA+UVB (PAB) treatments at 3 different solar irradiances which were obtained using neutral filters to simulate the PAR irradiance at different depths: no neutral filters (no NF, $5 \mathrm{~m}$ depth, $\square$ and $\cdots \cdots)$ ), 2 layers $(2 \mathrm{NF}, 10 \mathrm{~m}$ depth, $\mathrm{O}$ and ----$)$ and 4 layers (4NF, $20 \mathrm{~m}$ depth, $\Delta$ and - ) 
$\mathrm{p}=0.001,3$ April $F_{4,24}=6.06, \mathrm{p}=0.002,6$ April). This decrease was greater after $5 \mathrm{~d}$ than after $2 \mathrm{~d}$ of exposure (Fig. 4). \%D increased $\sim 4.8$ times from 2 to $5 \mathrm{~d}$ of exposure with no NF under the PAR treatment. After $2 \mathrm{~d}, \% \mathrm{D}$ was higher in PAB than in PAR. This trend was, however, reversed after $5 \mathrm{~d}$. No decrease or very low $\% \mathrm{D}$ was observed with $2 \mathrm{NF}$ and $4 \mathrm{NF}$. Full recovery of $F_{\mathrm{v}} / F_{\mathrm{m}}$ values was observed in all treatments.

After $2 \mathrm{~d}$ of incubation, the decrease in $F_{\mathrm{v}} / F_{\mathrm{m}}$ due to the irradiance treatment was greater in Ulva lactuca collected from the field than in those cultured under HNS conditions, i.e. different origins (Figs. $4 \& 5$; interaction $O \times t_{\mathrm{i}}: F_{4,48}=2.99, \mathrm{p}=0.028$ ). However, after $5 \mathrm{~d}$ of the experiment, a similar level of decrease was exhibited by the field collected algae under PAR treatment, whereas a much greater decrease was observed in the cultured algae when compared to the field collected algae in the presence of UV (PAB treatment) (Fig. 5 ; interactions $O \times \mathrm{UV}: F_{1,12}=6.37, \mathrm{p}=0.027$; $\left.O \times t_{\mathrm{i}}: F_{2,24}=4.53, \mathrm{p}=0.021\right) . \% \mathrm{D}$ was higher under PAB than under PAR in both field collected and cultured algae after 2 and $5 \mathrm{~d}$ with no NF. Under PAB, $\% \mathrm{D}$ was 2.6 and $1.6 \times$ higher with no NF than with $2 \mathrm{NF}$ after 2 and $5 \mathrm{~d}$ of exposure respectively. As in the field collected $U$. lactuca, cultured $U$. lactuca showed full recovery of $F_{\mathrm{v}} / F_{\mathrm{m}}$ values in all treatments.

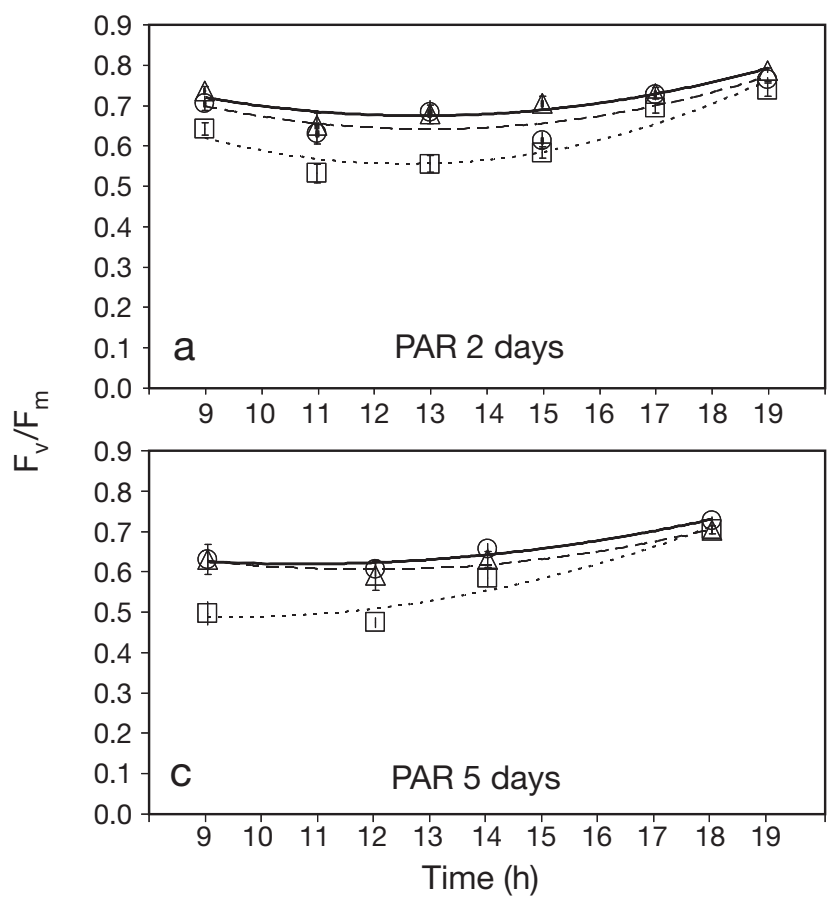

\section{Electron transport rate (ETR)}

Electron transport rates versus time are presented in Figs. 6-9. The result of statistical analysis is not shown since it is redundant with statistical analysis presented for $F_{\mathrm{v}} / F_{\mathrm{m}}$. In all cases, the differences among light treatments, i.e the effect of neutral filters, were significant.

Electron transport rate in Hypnea spinella exhibited hourly variation in response to hourly changes in irradiance (Fig. 6). ETR was higher in algae incubated with no $\mathrm{NF}$, followed by those under $2 \mathrm{NF}$ and $4 \mathrm{NF}$. After $2 \mathrm{~d}$ of incubation under the PAR treatment (Fig.6a), a $47 \%$ reduction in PAR irradiance under 2NF, compared to the no NF treatment, resulted in a 1.6-fold decrease in ETR with respect to the maximum ETR. In contrast, a $73 \%$ reduction in PAR irradiance under 4NF, compared to the no NF treatment, produced a 4 -fold decrease. After $2 \mathrm{~d}$ under PAB treatment, the decrease in maximum ETR between the no NF and the 2NF treatments was $\sim 1.85$ times, whereas that between the no NF and the $4 \mathrm{NF}$ treatments was 3.9 times (Fig. 6b). After 2 d, maximum ETR was higher under PAB than under PAR at noon in the no NF treatment, whereas no differences were found in both $2 \mathrm{NF}$ and $4 \mathrm{NF}$ treatments (Fig. 6a,b). However, after $5 \mathrm{~d}$ of the experiment, no differences in ETR among PAR and PAB treatments were found (Fig. 6c,d).
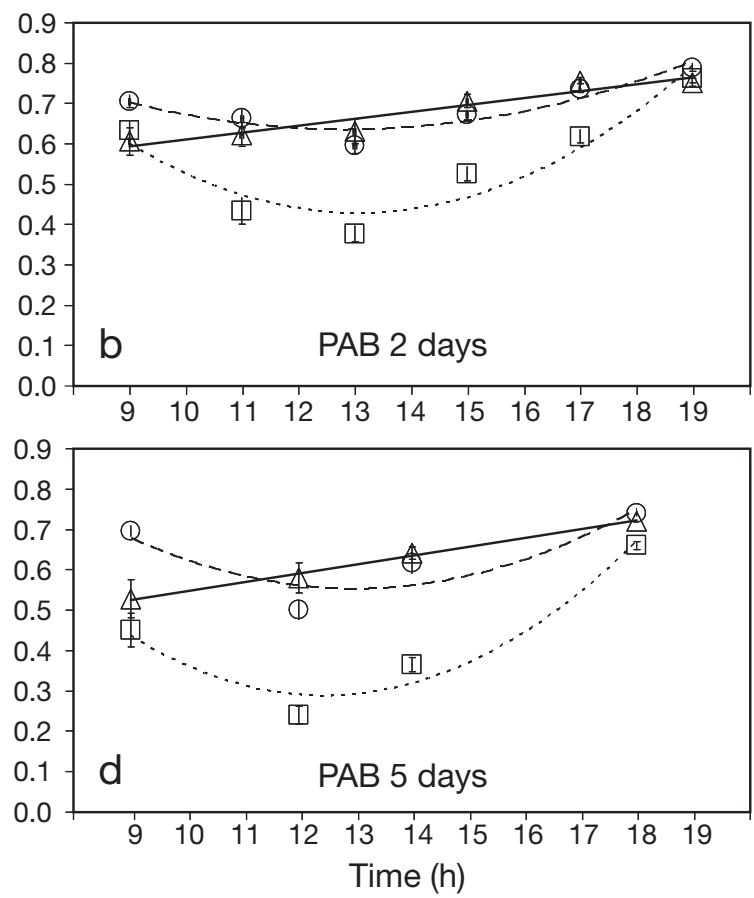

Fig. 5. Ulva lactuca. Mean $( \pm \mathrm{SE})$ daily cycles of maximum quantum yield $\left(F_{\mathrm{v}} / F_{\mathrm{m}}\right)$ of algae cultured under high nutrient supply condition (HNS) with fishpond effluents. $F_{\mathrm{v}} / F_{\mathrm{m}}$ was determined after $2 \mathrm{~d}$ (3 April 2008) (a,b) and 5 d (6 April 2008) (c,d) of experiments in algae incubated under PAR and PAR+UVA+UVB (PAB) treatments at 3 different solar irradiances which were obtained using neutral filters to simulate the PAR irradiance at different depths: no neutral filters (no NF, $5 \mathrm{~m} \mathrm{depth}, \square$ and $\cdots \cdots$ ), 2 layers (2NF, $10 \mathrm{~m}$ depth, $\mathrm{O}$ and ----$)$ and 4 layers (4NF, $20 \mathrm{~m}$ depth, $\Delta$ and - ) 

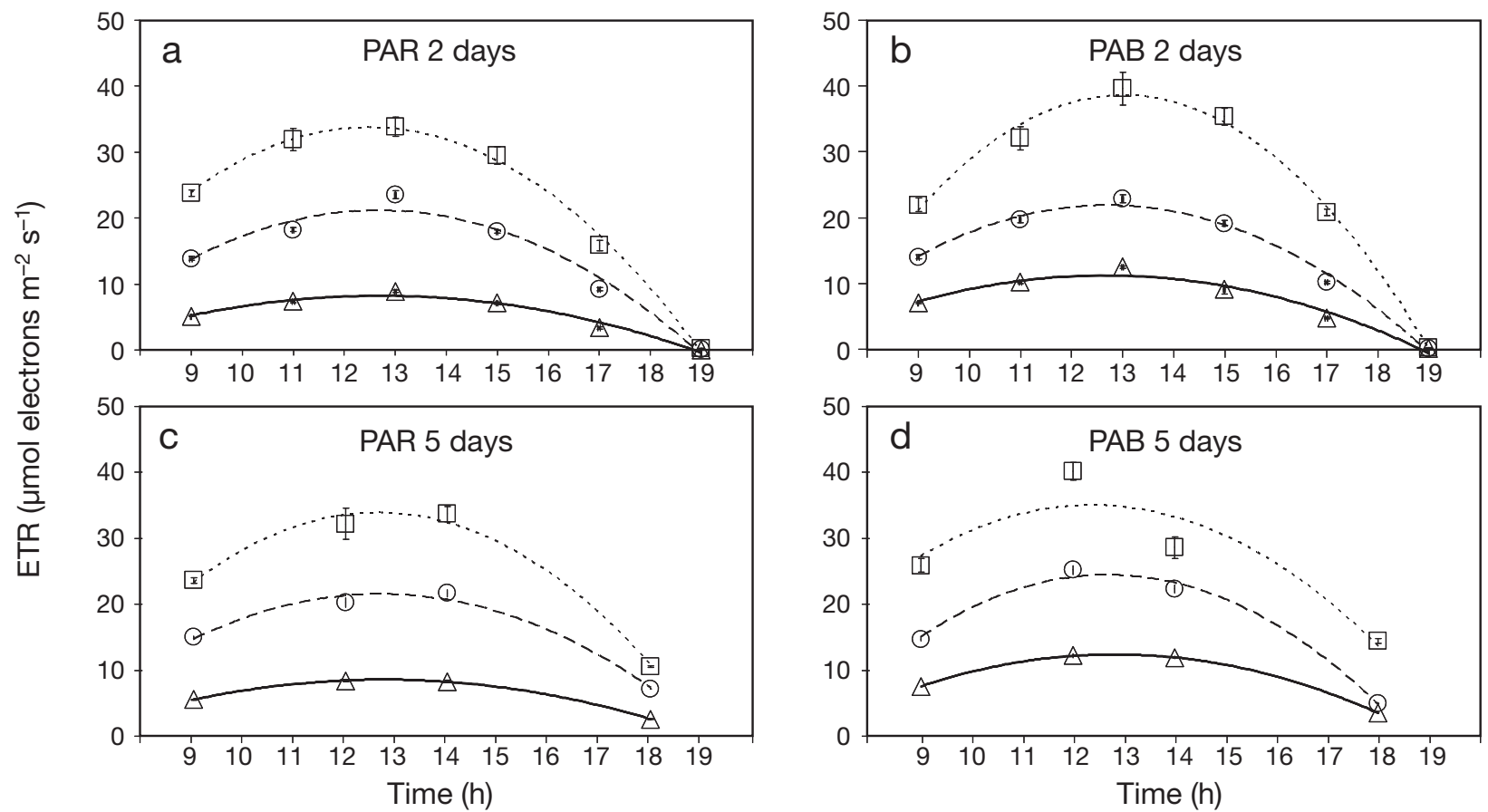

Fig. 6. Hypnea spinella. Mean $( \pm \mathrm{SE})$ electron transport rate (ETR) versus time for algae collected from the Red Sea at 3-4 m depth on 1 April 2008. ETR was determined after 2 d (3 April) (a,b) and 5 d (6 April) (c,d) of the experiment in algae incubated under PAR and PAB (PAR+UVA+UVB) treatments at 3 different solar irradiances which were obtained using neutral filters to simulate the PAR irradiance at different depths: no neutral filters (no NF, $5 \mathrm{~m}$ depth, $\square$ and $\cdots \cdots$ ), 2 layers $(2 \mathrm{NF}, 10 \mathrm{~m} \mathrm{depth}, \mathrm{O}$ and ---- ) and 4 layers $(4 \mathrm{NF}, 20 \mathrm{~m}$ depth, $\Delta$ and $\longrightarrow)$

ETRs through the day in Sargassum vulgare were similar with no NF and with $2 \mathrm{NF}$, both under PAR or PAB treatments (Fig. 7). Maximum ETR was higher after 5 than after $2 \mathrm{~d}$ under PAB treatment. UVR after $5 \mathrm{~d}$ of incubation elicited an increase in ETR with no NF or with 2NF (Fig. 7d). Maximum ETR after $2 \mathrm{~d}$ was $~ 3.5$ times higher with no NF than with $4 \mathrm{NF}$ under PAR treatment, whereas it was $\sim 2.6$ times higher under PAB treatment. After $5 \mathrm{~d}$, maximum ETR was $\sim 2.8$ times higher with no NF than with 4 NF under both PAR and PAB treatments.

For Ulva lactuca collected from the field, ETR was $~ 2$ times higher after 2 than after $5 \mathrm{~d}$ of treatment. While UVR reduced the maximum ETR after $2 \mathrm{~d}$ compared to PAR, no differences were eventually found among treatments after $5 \mathrm{~d}$ of exposure (Fig. 8). After $2 \mathrm{~d}$, maximum ETR with no NF under PAR treatment was 2 and 4 times higher than that with $2 \mathrm{NF}$ and $4 \mathrm{NF}$ respectively. In comparison, after $5 \mathrm{~d}$ under PAB treatment, maximum ETR with no NF was only 1.1 and 3.3 times higher than that with $2 \mathrm{NF}$ and $4 \mathrm{NF}$ respectively (Fig. 8). However, minor differences were found among the irradiance treatments after $5 \mathrm{~d}$ of incubation, i.e. under the PAR treatment, the maximum ETR with no NF was 2.5 times higher than that with $4 \mathrm{NF}$, whereas under the PAB treatment, the maximum ETR with no NF was only 2 times higher than that with $4 \mathrm{NF}$.
ETRs of cultured Ulva lactuca after $2 \mathrm{~d}$ of the experiment were higher under PAR than under PAB, particularly with no NF (Fig. 9). As in field collected U. lactuca, the ETR of cultured U. lactuca was higher after $2 \mathrm{~d}$ than after $5 \mathrm{~d}$ of exposure, although the differences were not as high. After $2 \mathrm{~d}$ under the PAR treatment, the maximum ETR with no NF was 1.6 and 4 times higher than that with $2 \mathrm{NF}$ and $4 \mathrm{NF}$ respectively. After $2 \mathrm{~d}$ under the PAB treatment, the corresponding factors were 1.4 and 4.3 times respectively. After $5 \mathrm{~d}$ under both PAR and PAB treatments, maximum ETR with no NF was 1.5 and 4 times higher than that with $2 \mathrm{NF}$ and 4 NF respectively (Fig. 9).

ETR values were highest in cultured Ulva lactuca (Fig. 9), followed by those in field collected algae in the following order: U. lactuca, (Fig. 8), Sargassum vulgare (Fig. 7) and Hypnea spinella (Fig. 6).

\section{Thallus absorptance}

The absorptances of different algal thalli at 400$700 \mathrm{~nm}$ (in relation to photosynthetic pigments) are presented in Table 3. Thallus absorptance was higher $(\mathrm{p}<0.046)$ in Sargassum vulgare and Ulva lactuca than in Hypnea spinella. After $5 \mathrm{~d}$ of incubation (6 April), the absorptance of $U$. lactuca decreased. For H. spin- 

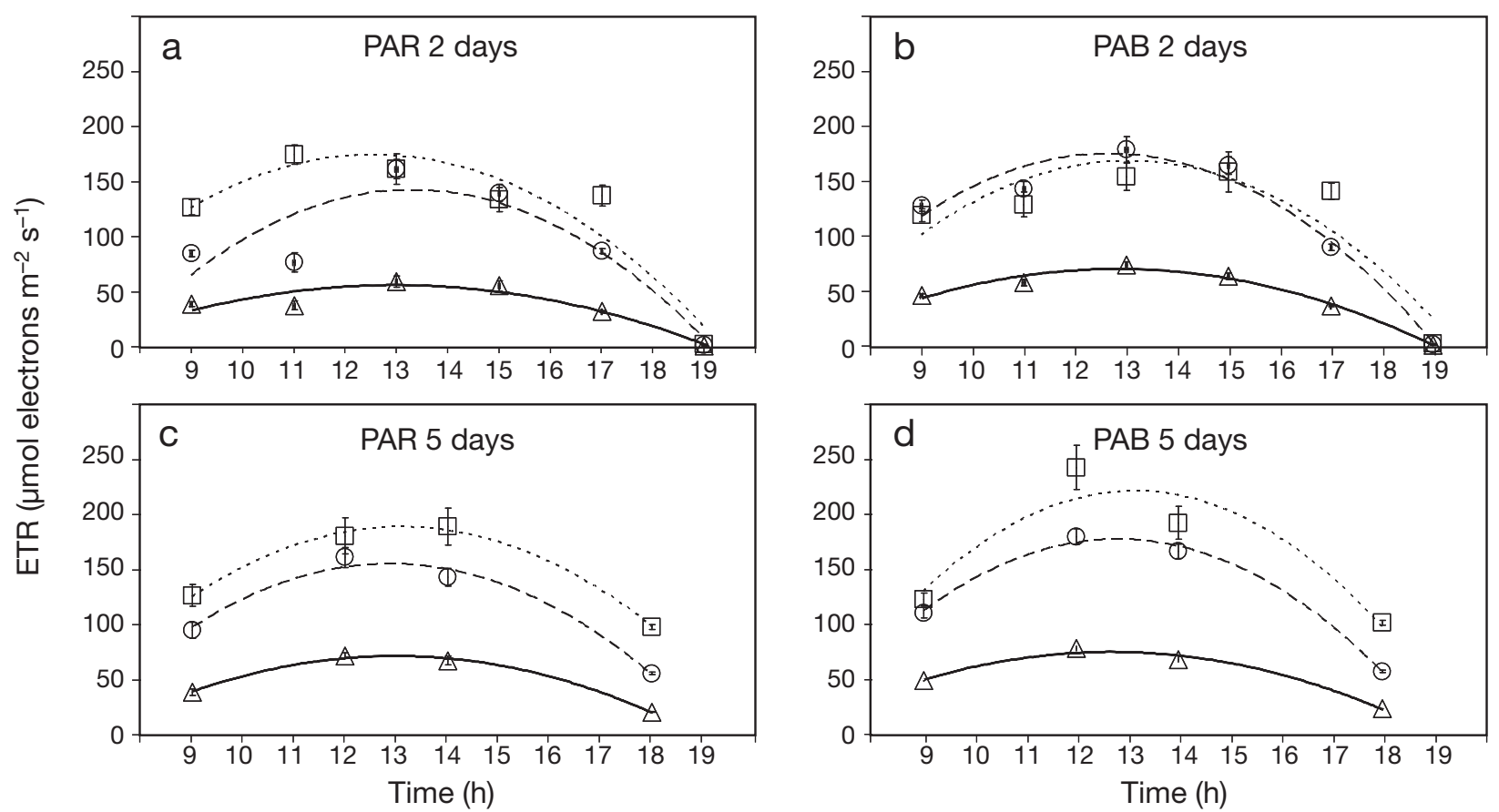

Fig. 7. Sargassum vulgare. Mean $( \pm \mathrm{SE})$ electron transport rate (ETR) versus time for algae collected from the Red Sea at $2-3 \mathrm{~m}$ depth on 1 April 2008. ETR was determined after $2 \mathrm{~d}$ (3 April) $(\mathrm{a}, \mathrm{b})$ and $5 \mathrm{~d}(6$ April) $(\mathrm{c}, \mathrm{d})$ of the experiment in algae incubated under PAR and PAB (PAR+UVA+UVB) treatments at 3 different solar irradiances which were obtained using neutral filters to simulate the PAR irradiance at different depths: no neutral filters (no NF, $5 \mathrm{~m}$ depth, $\square$ and $\cdots \cdots$ ), 2 layers $(2 \mathrm{NF}, 10 \mathrm{~m}$ depth,

$\mathrm{O}$ and ----$)$ and 4 layers (4NF, $20 \mathrm{~m}$ depth, $\Delta$ and - )
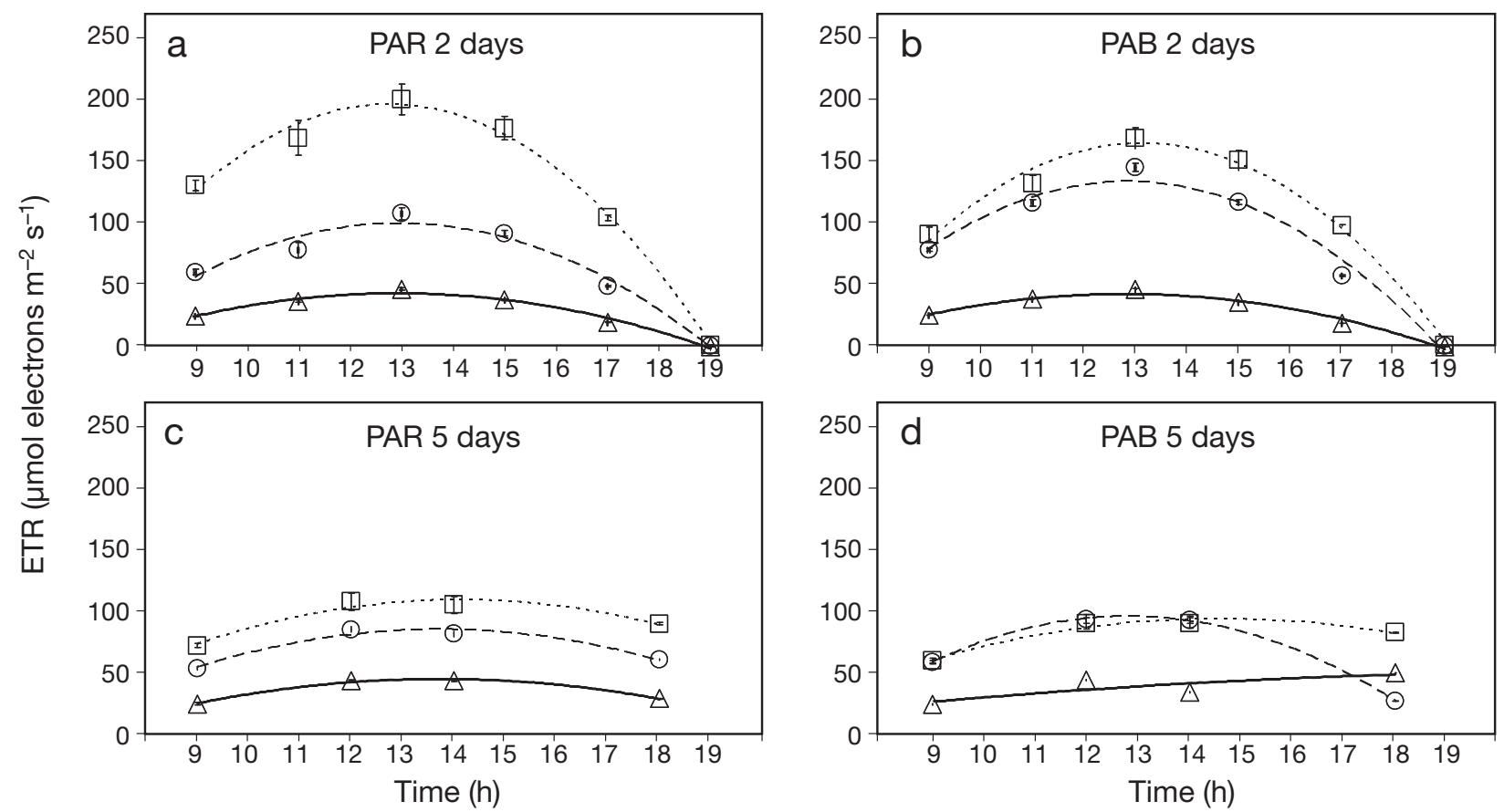

Fig. 8. Ulva lactuca. Mean $( \pm$ SE) electron transport rate (ETR) versus time for algae collected from the Red Sea at $1-2 \mathrm{~m}$ depth on 1 April 2008. ETR was determined after $2 \mathrm{~d}$ (3 April) $(\mathrm{a}, \mathrm{b})$ and $5 \mathrm{~d}$ (6 April) (c,d) of the experiment in algae incubated under PAR and PAB (PAR+UVA+UVB) treatments at 3 different solar irradiances which were obtained using neutral filters to simulate the PAR irradiance at different depths: no neutral filters (no NF, $5 \mathrm{~m}$ depth, $\square$ and $\cdots \cdots)$ ) 2 layers (2NF, $10 \mathrm{~m} \mathrm{depth,} \mathrm{O}$ and ----$)$ and 4 layers (4NF, $20 \mathrm{~m}$ depth, $\Delta$ and $\longrightarrow$ ) 

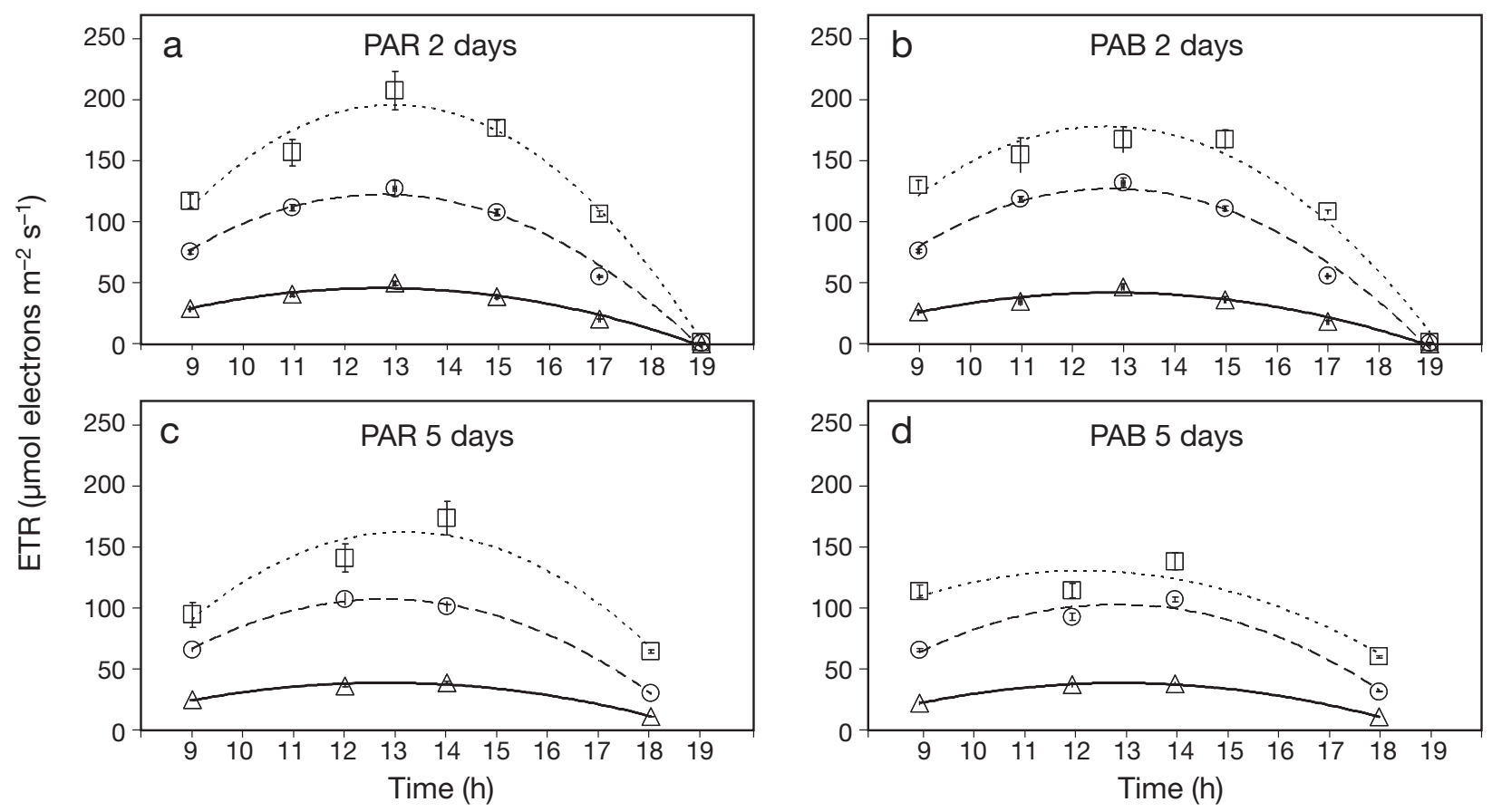

Fig. 9. Ulva lactuca. Mean $( \pm \mathrm{SE})$ electron transport rate (ETR) versus time for algae cultured under high nutrient supply (HNS) condition with fishpond effluents. ETR was determined after $2 \mathrm{~d}(3$ April) (a,b) and $5 \mathrm{~d}$ (6 April) (c,d) of the experiment in algae incubated under PAR and PAB (PAR+UVA+UVB) treatments at 3 different solar irradiances which were obtained using neutral filters to simulate the PAR irradiance at different depths: no neutral filters (no NF, $5 \mathrm{~m}$ depth, $\square$ and $\cdots \cdots), 2$ layers $(2 \mathrm{NF}, 10 \mathrm{~m}$ depth, $\mathrm{O}$ and ----) and 4 layers (4NF, $20 \mathrm{~m}$ depth, $\Delta$ and - )

ella, thallus absorptance increased after $2 \mathrm{~d}$ of incubation under the $2 \mathrm{NF}$ and $4 \mathrm{NF}$ treatments (Table 3). For S. vulgare, no differences in thallus absorptance under PAR or PAB were found, except under PAB after $5 \mathrm{~d}$ of incubation with no NF $(p<0.045)$. Under this treatment, the thallus absorptance decreased when compared to that under the PAB treatment after $2 \mathrm{~d}$ of incubation. Both at the initial time and after $2 \mathrm{~d}$ of the experiment, the thallus absorptances of $U$. lactuca collected from the field were slightly lower than those of cultured U. lactuca under HNS conditions (Table 3). After $2 \mathrm{~d}$ of incubation, the thallus absorptances of $U$. lactuca collected from the field did not show any differences under either PAR or PAB treatments, as was also observed for cultured U. lactuca. However, after $5 \mathrm{~d}$ of incubation, the thallus absorptances of field collected U. lactuca decreased under the no NF and $2 \mathrm{NF}$ treatments. This decrease (comparing data for 3 and 6 April) was greater than that in cultured $U$. lactuca (Table 3). Never-
Table 3. Hypnea spinella, Sargassum vulgare and Ulva lactuca. Absorptance (mean $\pm \mathrm{SE}$ ) at $400-700 \mathrm{~nm}$ for thalli collected in the Red Sea and of U. lactuca cultured under high nutrient supply (HNS) conditions with fishpond effluents. Measurements were taken at the initial time (1 April 2008) and after $2 \mathrm{~d}$ (3 April $2008)$ and $5 \mathrm{~d}$ (6 April 2008) of incubation under PAR (400-700 nm) or full solar radiation (PAB: PAR+UVA+UVB) with incident irradiance being reduced by using neutral filters (grey nets). No NF: no neutral filters, 2NF: 2 layers and 4NF: 4 layers. $\mathrm{N}=6$

\begin{tabular}{|lcccc}
\hline $\begin{array}{l}\text { Date and } \\
\text { treatment }\end{array}$ & $\begin{array}{c}\text { H. spinella } \\
\text { field }\end{array}$ & $\begin{array}{c}\text { S. vulgare } \\
\text { field }\end{array}$ & field & $\begin{array}{c}\text { lactuca } \\
\text { culture, HNS }\end{array}$ \\
\hline $\begin{array}{l}\text { 1 April 2008 } \\
\text { (initial) }\end{array}$ & $0.59 \pm 0.072$ & $0.77 \pm 0.091$ & $0.75 \pm 0.081$ & $0.78 \pm 0.068$ \\
3 April 2008, PAR & & & & \\
No NF & $0.66 \pm 0.072$ & $0.85 \pm 0.074$ & $0.76 \pm 0.110$ & $0.79 \pm 0.091$ \\
2NF & $0.69 \pm 0.081$ & $0.86 \pm 0.101$ & $0.67 \pm 0.120$ & $0.74 \pm 0.097$ \\
4NF & $0.63 \pm 0.061$ & $0.88 \pm 0.092$ & $0.72 \pm 0.112$ & $0.79 \pm 0.110$ \\
3 April 2008, PAB & & & & \\
No NF & $0.79 \pm 0.083$ & $0.86 \pm 0.051$ & $0.68 \pm 0.126$ & $0.75 \pm 0.085$ \\
2NF & $0.63 \pm 0.072$ & $0.92 \pm 0.032$ & $0.73 \pm 0.093$ & $0.78 \pm 0.091$ \\
4NF & $0.79 \pm 0.045$ & $0.87 \pm 0.063$ & $0.66 \pm 0.086$ & $0.79 \pm 0.068$ \\
6 April 2008, PAR & & & & \\
No NF & $0.58 \pm 0.168$ & $0.82 \pm 0.021$ & $0.31 \pm 0.054$ & $0.43 \pm 0.043$ \\
2NF & $0.58 \pm 0.158$ & $0.82 \pm 0.040$ & $0.52 \pm 0.136$ & $0.58 \pm 0.052$ \\
4NF & $0.57 \pm 0.062$ & $0.83 \pm 0.075$ & $0.76 \pm 0.095$ & $0.79 \pm 0.084$ \\
6 April 2008, PAB & & & & \\
No NF & $0.70 \pm 0.196$ & $0.80 \pm 0.018$ & $0.29 \pm 0.033$ & $0.36 \pm 0.051$ \\
2NF & $0.61 \pm 0.041$ & $0.81 \pm 0.015$ & $0.49 \pm 0.045$ & $0.53 \pm 0.089$ \\
4NF & $0.75 \pm 0.062$ & $0.84 \pm 0.094$ & $0.69 \pm 0.067$ & $0.71 \pm 0.052$ \\
\hline
\end{tabular}


theless, after $5 \mathrm{~d}$ of the experiment, no differences in thallus absorptances of both field collected and cultured algae were observed between PAR and PAB treatments.

\section{DISCUSSION}

\section{Dynamic photoinhibition: effects of PAR and UVR}

Despite the high UV penetration in the Red Sea (Stambler 2005) and incidents of macroalgal blooms attributable to nutrient enrichment with negative effects on corals (Mergener 1981, Genin et al. 1995), only a few studies on photosynthesis and growth of macroalgae from the Red Sea have been conducted. This is in sharp contrast to studies in other major coral reef regions around the world (Lapointe 1997, Bellwood et al. 2004, Smith et al. 2005). The high irradiance and the transparency of shallow waters in the Red Sea intuitively suggest that macroalgae growing there should have developed more efficient photoprotective mechanisms to tolerate light stress than species from other biogeographical regions with less daily integrated irradiance (Lüning 1990). Photoinhibition has been proposed as a strategy for photoprotection against high irradiance (Hanelt 1998). Several studies focusing on the effects of natural UVR on the photosynthetic performance of macroalgae from high exposure environments have revealed that the occurrence of photoinhibition under high solar radiation depends basically on daily changes in the level of irradiance, algal position on the shore, vertical light attenuation, or a combination of all these factors (Figueroa et al. 1997, Flores-Moya et al. 1998).

Maximum quantum yield $\left(F_{\mathrm{v}} / F_{\mathrm{m}}\right)$ and maximum ETR in seaweeds collected from the Red Sea were found to decrease largely due to the combined effects of increased irradiance (PAR) and the presence of UVR. In the present study, photoinhibition in the studied species was greater under the no NF treatment that simulated a $5 \mathrm{~m}$ water depth environment, than with $2 \mathrm{NF}$ and $4 \mathrm{NF}$ that simulated 10 and $20 \mathrm{~m}$ water depth environments respectively. The highest sensitivity to irradiance exhibited by Hypnea spinella is likely related to its position in the subtidal zone (see below). Deep-water algae and those adapted to shade conditions are inhibited faster when exposed to direct solar radiation (see Häder \& Figueroa 1997, Bischof et al. 2006). For Ulva lactuca and Sargassum vulgare, full recovery was observed, whereas only partial recovery was found in $H$. spinella on 3 April (the second day of the experiment), with increasing recovery on 6 April (the fifth day of the experiment). This indicates that the algae exhibited a certain level of acclimation over a short-term period. Thus, dynamic photoinhibition appears to be ac- tive in the species analyzed, consistent with that described for other high exposure macroalgae (Figueroa et al. 1997). Macroalgae show pronounced photoinhibition after various time periods of exposure at high zenith angles to unfiltered, direct solar radiation at the surface (Flores-Moya et al. 1998, Gao \& Xu 2008). Even algae from rock pools, which are naturally exposed to extreme solar irradiances, show signs of photoinhibition after extended periods of exposure (Figueroa et al. 1997, Figueroa \& Gómez 2001, Bischof et al. 2006).

It may be argued that because the highest level of exposure with no NF in this experiment corresponded to a calculated $5 \mathrm{~m}$ water depth environment (according to the $K_{\mathrm{d}}$ values reported by Stambler 2005), the algae should have received a lower daily integrated irradiance than in their natural environment (which is shallower at only 1-4 m deep); hence, no photoinhibition should have been expected. However, since the algae growing in the experimental tanks were all floating with little movement, rather than attached as they would be in the natural environment, their exposure to irradiance was expected to be higher than what would be estimated from a higher sun exposure of the thallus surface. In addition, increased exposure to irradiance might have also resulted due to the form of the incubator, i.e. a cylinder, that produces the effect of a lens. The irradiance might have also increased due to the high reflection by the white colour of the tank bottom (Villafañe et al. 2003).

Photoinhibition (as \%D in $F_{\mathrm{v}} / F_{\mathrm{m}}$ from morning to noon) increased under only the PAR treatment in several species and at different times. In Sargassum vulgare, short-term (2 d) photoinhibition was higher than that in the mid term (5 d), indicating a certain degree of acclimation under both PAR and PAB treatments. However, in the cultured Ulva lactuca, this temporal pattern was observed under PAR but not under $\mathrm{PAB}$. The level of photoinhibition under the PAB treatment was constant, indicating that UVR may produce an additional stress on the algae. In field collected $U$. lactuca, the level of photoinhibition increased with exposure time. The different capacities for acclimation could be due to the positive effect of nutrient supply on photoprotection (see below). It has been shown that exclusion of UVR resulted in a 10 to $65 \%$ increase in photosynthetic quantum yield in algae from the Mediterranean (Jiménez et al. 1998) or a 17 to $46 \%$ increase in intertidal algae from southern Chile (Gómez et al. 2004). In the North Sea, however, transplantation experiments did not produce such a high difference in photosynthetic quantum yield between algae exposed to full solar radiation and those exposed to total exclusion of UVR, i.e. only a 15 to $20 \%$ increase in photosynthetic quantum yield was found in Laminaria saccharina (Hanelt et al. 1997). 
Surprisingly, after $2 \mathrm{~d}$ of exposure of Hypnea spinella to full irradiance (no NF) and after $5 \mathrm{~d}$ for field collected Ulva lactuca, photoinhibition was lower under PAB than under only PAR. UVB under high PAR irradiance can even have beneficial effects on photobiological processes, e.g. in the brown alga Dictyota dichotoma (Flores-Moya et al. 1999), in the green macroalga Ulva pertusa (Han \& Han 2005) and in several shallow water tropical algae (Hanelt \& Roleda 2009). Persistence of the inhibitory effect in the PAR+UVA treatment (absence of UVB) led Flores-Moya et al. (1999) to suggest that UVA radiation exerts the main role in photoinhibition and UVB may be involved both in the impairment and the recovery of photosynthesis. Thus, UVB may not only cause negative effects on photosynthesis, but may also support recovery processes in macrophytes adapted to a high UVR environment in contrast to those growing in habitats with lower natural UVR exposure (Hanelt et al. 2006, Hanelt \& Roleda 2009).

\section{Bio-optical properties: thallus absorptance}

The different photosynthetic responses to increasing irradiance or to the presence of UVR may be related to the different bio-optical properties of the algae used. Pigment concentration and composition and thallus thickness and form are the main biological factors that contribute to algal acclimation to the underwater environment (Enríquez et al. 1995). Thallus morphology, thickness and pigmentation strongly determine the light harvesting capacity. The various cell layers, which are characterized by different optical properties, may cause self-shading and light scattering, which in turn result in differential light absorption (Raven \& Kübler 2002). In our study, the absorptance was much higher in the branched algae Hypnea spinella and Sargassum vulgare, compared to that in the laminar, 2 cell layer, field collected Ulva lactuca. Pigmentation also varies between species and morphs, and may also be related to the taxonomic group; i.e. accessory pigments such as phycobilins in red algae also contribute to increases in their absorptance. However, photosynthetic capacity (ETR values) and recovery were lower in thick thallus species (e.g. H. spinella) than in thin thallus ones (e.g. U. lactuca). Johansson \& Snoeijs (2002) showed that thinner thalli recovered better after UV treatment than thicker algae. The higher photoprotection in $H$. spinella under PAB than under PAR in the short term $(2 \mathrm{~d})$ appears to be related to thallus absorptance since this parameter was higher under PAB than under PAR

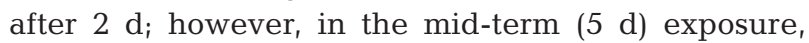
both thallus absorptance and $F_{\mathrm{v}} / F_{\mathrm{m}}$ decreased with in- creasing irradiance. The inverse relation between thallus absorptance and photoinhibition, and the effect of UVR have been shown under laboratory conditions in other red algal species such as Porphyra leucosticta. Thallus absorptance is a better indicator of acclimation than pigment content since the former integrates the effect of both pigment content and thallus thickness (Aguilera et al. 2008). In this study, photosynthetic capacity was higher in the sheet thallus species $U$. lactuca than in the branched and thicker algae $H$. spinella and S. vulgare. This result agrees well with the reported relationship between morphology and primary production among seaweeds (Littler et al. 1983, Enríquez et al. 1995, 1996).

\section{Nutrient conditions and photoprotection capacity}

Low nutrient supply is a limiting factor for seaweed productivity in coral reefs. The frequency of algal blooms on coral reefs has increased in the last several decades, including reefs in the Red Sea (Mergener 1981, Hughes 1994, Bellwood et al. 2004). Smith et al. (2005) reported the filamentous green alga Cladophora sericea to be forming ephemeral blooms in coral reefs of Hawaii. Using relative ETR as an indicator of photosynthesis, they demonstrated that these algal samples were nutrient limited. Nutrient limitation has been associated with increased vulnerability to photoinhibition by PAR and UVR in macroalgae (Döhler et al. 1995, Korbee Peinado et al. 2004). Algae in the Red Sea are exposed to low nutrient conditions (Klinker et al. 1978). This could reduce their capacity for photoprotection as nitrogen is needed for the accumulation of UV screening substances such as mycosporine-like amino acids in red algae (Korbee Peinado et al. 2004, Huovinen et al. 2006) and phenolic compounds in brown algae (Pavia \& Toth 2000). Ulva lactuca, the species that showed the highest recovery and photosynthetic capacity in our experiments, was collected close to the harbour of Eilat, where higher nutrient supply in the water is expected. In comparison, Нypnea spinella and Sargassum vulgare were collected close to the Interuniversity Institute with lower average concentration of nutrients (Table 1) (Klinker et al. 1978). Not surprisingly, the HNS cultured U. lactuca showed the highest photosynthetic capacity (ETR) and highest acclimation through the $5 \mathrm{~d}$ exposure period. In addition, the cultured $U$. lactuca also exhibited higher recovery and lower decrease in thallus absorptance than field collected U. lactuca. Figueroa et al. (2009) reported both higher photosynthetic and photoprotective capacities against increased UVR and temperature in $U$. lactuca cultured under high rather than under low nutrient conditions. 


\section{CONCLUSIONS}

This study shows that the highest ETR values, the smallest decrease in $F_{\mathrm{v}} / F_{\mathrm{m}}$ at noon (indicator of photoinhibition) and the highest recovery of $F_{\mathrm{v}} / F_{\mathrm{m}}$ values in the afternoon were all observed in Ulva lactuca, which is the species that was collected in shallow water (1-2 m depth). This was followed by Sargassum vulgare (2-3 m depth) and Hypnea spinella (3-4 m depth). Thus, the capacity for acclimation or resistance to hourly variation in solar radiation appears to be correlated with the depth zonation of the species. This suggests that algae collected in surface waters should exhibit more efficient photoprotective mechanisms. The greater activation of photoprotective mechanisms in U. lactuca than in S. vulgare, followed by $H$. spinella, also indicates that dynamic photoinhibition and other expected mechanisms such as production of UV screening and antioxidant substances could also be related to the depth zonation (light history) of the species. In addition, although the HNS cultured U. lactuca is a shade-grown algae (Figueroa et al. 2009), it exhibited a very high capacity for acclimation to high irradiance (high recovery) and the highest photosynthetic capacity (ETR). This could be largely due to the positive effect of nutrient supply on photoprotection. This baseline information on the ecophysiology of macroalgae in the coral reef regions of the Red Sea could aid our understanding of the dynamics of the reef system, which are essential for the development of management plans and conservation strategies against their further decline.

Acknowledgements. We thank the Batsheva de Rothschild Foundation, Bar Ilan University, the Moshe Shilo Center for Marine Biogeochemistry, and the staff of the Interuniversity Institute for funding and logistic support. F.L.F. and B.M. thank the financial support of the Ministry of Science and Technology of Spain (Projects AGL2005-02655, CGL200766095/BOS and CGL2008 05407-C03-01). This research was supported by Research Grant Award No IS-3853-06 from BARD, the United States-Israel Binational Agricultural Research and Development Fund to A.I.. This study was conducted during the 8th International Workshop of the Group for Aquatic Primary Productivity (GAP) and the Batsheva de Rothschild Seminar on Gross and Net Primary Productivity held at the Interuniversity Institute for Marine Sciences, Eilat, Israel in April 2008.

\section{LITERATURE CITED}

Aguilera J, Figueroa FL, Häder DP, Jiménez C (2008) Photoinhibition and photosynthetic pigment reorganisation dynamics in light/darkness cycles as photoprotective mechanisms of Porphyra umbilicalis against damaging effects of UV radiation. Sci Mar 72:87-97

$>$ Beer S, Ilan M, Eshel A, Weil A, Brickner I (1998a) Use of amplitude modulated (PAM) fluorometry for in situ mea- surements of photosynthesis in two Red Sea flavoid corals. Mar Biol 131:607-612

Beer S, Vilenkin B, Weil A, Veste M, Susel L, Eshel A (1998b) Measuring photosynthetic rates in seagrasses by pulse amplitude modulated (PAM) fluorometry. Mar Ecol Prog Ser 174:293-300

> Beer S, Larsson C, Poryan O, Axelsson L (2000) Photosynthetic rates of Ulva lactuca (Chlorophyta) measured by pulse amplitude modulated (PAM) fluorometry. Eur J Phycol 35:69-74

> Bellwood DR, Hughes TP, Folke C, Nyström M (2004) Confronting the coral reef crisis. Nature 429:827-833

Bischof K, Gómez I, Molis M, Hanelt D and others (2006) Ultraviolet radiation shapes seaweed communities. Rev Environ Sci Biotechnol 5:141-166

$>$ Döhler G, Hagmeier E, David C (1995) Effects of solar and artificial UV radiation on pigments and assimilation of ${ }^{15} \mathrm{~N}$ ammonium and ${ }^{15} \mathrm{~N}$ nitrate by macroalgae. J Photochem Photobio B 30:179-187

- Enríquez S, Duarte CM, Sand-Jensen K (1995) Patterns in the photosynthetic metabolism of Mediterranean macrophytes. Mar Ecol Prog Ser 119:243-252

Enríquez S, Duarte CM, Sand-Jensen K, Nielsen SL (1996) Broad-scale comparison of photosynthetic rates across photoautotrophic organisms. Oecologia 108:197-206

Falkowski PG, Dubinsky Z (1981) Light-shade adaptation of Stylophora pistillata, a hermatypic coral from the Gulf of Eilat. Nature 289:172-174

Figueroa FL, Gómez I (2001) Photosynthetic acclimation to solar UV radiation of marine red algae from the warmtemperate coast of southern Spain. A review. J Appl Phycol 13:233-245

Figueroa FL, Salles S, Aguilera J, Jiménez C and others (1997) Effects of solar radiation on photoinhibition and pigmentation in the red alga Porphyra leucosticta. Mar Ecol Prog Ser 151:81-90

Figueroa FL, Conde-Álvarez R, Gómez I (2003) Relations between electron transport rates determined by pulse amplitude modulated chlorophyll fluorescence and oxygen evolution in macroalgae under different light conditions. Photosyn Res 75:259-275

Figueroa FL, Israel A, Neori A, Martínez B, Malta E, Ang P, Inken S, Marquardt R, Korbee N (2009) Effects of nutrient supply on photosynthesis and pigmentation in Ulva lactuca (Chlorophyta): responses to short-term stress. Aquat Biol 7:173-183

> Flores-Moya A, Gómez I, Viñegla B, Altamirano M and others (1998) Effects of solar radiation on the endemic Mediterranean red alga Rissoella verruculosa: photosynthetic performance, pigment content and the activities of enzymes related to nutrient uptake. New Phytol 139:673-683

> Flores-Moya A, Hanelt D, Figueroa FL, Altamirano M, Viñegla B, Salles S (1999) Involvement of solar UV-B radiation in recovery of inhibited photosynthesis in the brown alga Dictyota dichotoma (Hudson) Lamoroux. J Photochem Photobio B 49:129-135

> Gao K, Xu J (2008) Effects of solar UV radiation on diurnal photosynthetic performance and growth of Gracilaria lemaneiformis (Rhodophyta). Eur J Phycol 43:297-307

Genin A, Lazar B, Brenner S (1995) Vertical mixing and coral depth in the Red Sea following the eruption of Mt. Pinatubo. Nature 377:507-510

Genty B, Briantais JM, Baker NR (1989) The relation between the quantum yield of photosynthetic electron transport and quenching of chlorophyll fluorescence. Biochim Biophys Acta 990:87-92

Godínez-Ortega JL, Snoeeijs P, Robledo D, Freile-Peregrin Y, 
Pedersén M (2008) Growth and pigment composition in the red alga Halymenia floresii cultured under different light qualities. J Appl Phycol 20:253-260

Gómez I, Figueroa FL, Ulloa N, Morales V, Lovengreen C, Huovinen C, Hess S (2004) Patterns of photosynthetic performance in intertidal macroalgae from southern Chile in relation to solar radiation. Mar Ecol Prog Ser 270:103-116

Grasshoff K, Ehrhardt M, Kremling K (1983) Methods of seawater analysis. Verlag Chemie, Weinheim, Germany

Grzymski J, Johnsen G, Sakshaug E (1997) The significance of intracellular self-shading on the bio-optical properties of brown, red and green macroalgae. J Phycol 33:408-414

Häder DP, Figueroa FL (1997) Photoecophysiology of marine macroalgae. Photochem Photobiol 66:1-14

> Han YS, Han T (2005) UV-B induction of UV-B protection in Ulva pertusa (Chlorophyta). J Phycol 41:523-530

Hanelt D (1998) The capability for dynamic photoinhibition in Arctic macroalgae is related to their depth distribution. Mar Biol 131:361-369

Hanelt D, Roleda MY (2009) UVB radiation may ameliorate photoinhibition in specific shallow-water tropical marine macrophytes. Aquat Bot 91:6-12

Hanelt D, Li J, Nultsch W (1994) Tidal dependence of photoinhibition of photosynthesis in marine macrophytes of the South China sea. Bot Acta 107:66-72

> Hanelt D, Melchersmann B, Wiencke C, Nultsch W (1997) Effects of high light stress on photosynthesis of polar macroalgae in relation to depth distribution. Mar Ecol Prog Ser 149:255-266

Hanelt D, Hawes I, Rae R (2006) Reduction of UVB causes an enhancement of photoinhibition in high light stressed aquatic plants from New Zealand lakes. J Photochem Photobio B 84:89-102

Hughes TP (1994) Catastrophes, phase-shifts and largescale degradation of a Caribbean coral reef. Science 265: 1547-1551

Huovinen P, Matos J, Sousa-Pinto I, Figueroa FL (2006) The role of ammonium in photoprotection against high irradiance in the red alga Grateloupia lanceola. Aquat Bot 84: 308-316

Jiménez C, Figueroa FL, Salles S, Aguilera J and others (1998) Effects of solar radiation on photosynthesis and photoinhibition in red macrophytes from an intertidal system of southern Spain. Bot Mar 41:329-338

Johansson G, Snoeijs P (2002) Macroalgal photosynthetic responses to light in relation to thallus morphology and depth zonation. Mar Ecol Prog Ser 244:63-72

Submitted: December 1, 2008; Accepted: August 21, 2009
Klinker J, Reiss Z, Kropach C, Levanon I, Harpaz H, Shapiro $\mathrm{Y}$ (1978) Nutrients and biomass distribution in the Gulf of Aqaba (Eilat), Red sea. Mar Biol 45:53-64

Korbee Peinado N, Abdala Díaz RT, Figueroa FL, Helbling EW (2004) Ammonium and UV radiation stimulate the accumulation of mycosporine-like amino acids in Porphyra columbina (Rhodophyta) from Patagonia, Argentina. J Phycol 40:248-259

Lapointe BE (1997) Nutrient thresholds for bottom-up control of macroalgal blooms on coral reefs in Jamaica and southeast Florida. Limnol Oceanogr 42:1119-1131

Littler MM, Littler DS, Taylor PR (1983) Evolutionary strategies in a tropical barrier reef system: functional-form groups of marine macroalgae. J Phycol 19:229-237

Lüning K (1990) Seaweeds. Their environment, biogeography, and ecophysiology. John Wiley \& Sons, New York, p 527

Mergener H (1981) Man-made influences on and natural changes in the settlement of the Aqaba reefs (Red Sea). Proc 4th Int Coral Reef Symp 1:193-207

Pavia H, Toth GB (2000) Influence of nitrogen on the phlorotannin content of the brown seaweeds Ascophyllum nodosum and Fucus vesiculosus. Hydrobiologia 440:299-305

Payri CE, Maritorena S, Bizeau C, Rodiére M (2001) Photoacclimation in the tropical coralline alga Hydrolithon onkodes (Rhodophyta, Corallinaceae) from a French Polynesian reef. J Phycol 37:223-234

Raven JA, Kübler JE (2002) New light on the scaling of metabolic rate with the size of algae. J Phycol 38:11-16

Schreiber U, Endo T, Mi H, Asada K (1995) Quenching analysis of chlorophyll fluorescence by the saturation pulse method: particular aspects relating to the study of eukaryotic algae and cyanobacteria. Plant Cell Physiol 36:873-882

Smith JE, Runcie JW, Smith CM (2005) Characterization of a large-scale ephemeral bloom of the green alga Cladophora sericea on the coral reefs of West Maui, Hawaii. Mar Ecol Prog Ser 302:77-91

Stambler N (2005) Bio-optical properties of the northern Red Sea and the Gulf of Eilat (Aqaba) during winter 1999. J Sea Res 54:186-203

Underwood T (1997) Experiments in ecology. Their logical design and interpretation using analysis of variance. Cambridge University Press, Cambridge, UK

Villafañe VE, Sundbäck K, Figueroa FL, Helbling EW (2003) Photosynthesis in the aquatic environment as affected by UVR. In: Helbling EW, Zagarese HE (eds) UV effects in aquatic organisms and ecosystems, The Royal Society of Chemistry, Cambridge, UK, p 357-397

Proofs received from author(s): September 17, 2009 